\title{
Post-synthesis reshaping of gold nanorods using a femtosecond laser
}

\author{
Marta Gordel, ${ }^{\star a b}$ Joanna Olesiak-Banska, ${ }^{a}$ Katarzyna Matczyszyn, ${ }^{\text {*a }}$ \\ Claude Nogues, ${ }^{b}$ Malcolm Buckle ${ }^{b}$ and Marek Samoc ${ }^{a}$
}

Received 14th August 2013. Accepted 24th October 2013

DOI: $10.1039 / \mathrm{c} 3 \mathrm{cp} 53457 \mathrm{j}$

www.rsc.org/pccp
This work describes the interaction between femtosecond laser pulses ( 130 fs, $800 \mathrm{~nm}$ ) and gold nanorods (NRs) leading to reshaping of the NRs. We focus on the investigation of structural changes of the NRs and the parameters influencing the reshaping, like surface modification using sodium sulphide, laser power and the position of the longitudinal surface plasmon resonance band (I-SPR) with respect to the laser wavelength. A thermogravimetric analysis experiment is performed to examine changes in the composition of NRs upon heating. A new type of banana-shaped NPs is described and the conditions of their appearance are discussed.

\section{Introduction}

Due to the potential technological applications of metal nanoparticles (NPs) and nanostructures, an ever-increasing number of publications report on their fabrication and optical properties. Since the optical, electrical, and catalytic properties of gold NPs are both size and shape dependent, much effort has been expended towards the control of their mean size, shape, and surface state, through adjusting the conditions of their synthesis. ${ }^{1-6}$ However, such control can also be achieved through various post-synthesis treatments, e.g. the treatment of already prepared NPs by a low power femtosecond laser can be used to increase the monodispersity of nanoparticles. ${ }^{7}$ This can also introduce new shapes, with potentially interesting linear and nonlinear optical properties, which cannot be normally obtained during synthesis, by selection of the particles with an appropriate longitudinal surface plasmon band position with respect to the laser wavelength, laser pulse power and width. Structure of the gold nanorods (NRs) could be changed to spherical during irradiation, using pulsed femtosecond (fs) and nanosecond (ns) lasers. ${ }^{7-11}$ The experiments described by Link and co-workers carried out with two different lasers: ns at $355 \mathrm{~nm}$ and fs at $800 \mathrm{~nm}$ led to the conclusion that both laser types cause photothermal reshaping of NRs in aqueous solution. ${ }^{7-9}$ In the case of the fs laser, the energy threshold for complete melting of NRs was reduced by a factor of 100 ,

\footnotetext{
${ }^{a}$ Institute of Physical and Theoretical Chemistry, Wroclaw University of Technology, Wyb. Wyspianskiego 27, 50-370 Wroclaw, Poland.

E-mail: marta.gordel@pwr.wroc.pl, katarzyna.matczyszyn@pwr.wroc.pl; Fax: +48-71-320-33-64; Tel: +48-71-320-38-81

${ }^{b}$ LBPA, UMR 8113 CNRS. ENS de Cachan, 61 Avenue du President Wilson,

94235 Cachan, France. Tel: +33-1-47-40-76-70
}

in comparison with the ns laser. Similar experiments were performed by Chang et al. using ns lasers $(532 \mathrm{~nm}, 1064 \mathrm{~nm}) .{ }^{10}$ The photoannealing process of conversion of rods to spheres was described and a new type of " $\varphi$-shaped" gold NPs (nanorods with a convex deformation in the middle) was observed in the case of $1064 \mathrm{~nm}$ irradiation. The " $\varphi$-shaped" gold NPs possibly appear to be the first stage of a shape transformation. The exact procedure of transformation of long and thin nanorods into spheres involving an increase in nanorod width and decrease of its length was reported by Zijlstra et al., who examined a single NR under fs laser irradiation. ${ }^{11}$

The difference in behavior of NRs irradiated with fs and ns laser pulses is determined by the timescale of processes following absorption. ${ }^{8}$ The high power femtosecond laser produces nonlinear effects causing ionization of the surface, charge repulsion and transformation of NRs into the most thermodynamically stable form, which is spherical. A nanosecond laser also causes nonlinear processes, but the dominant effect on the sample comes from cumulative thermal effects, leading to melting and finally fragmentation of the NPs. One can describe the process occurring after photon absorption as an evolution over time. ${ }^{12-14}$ The process, taking place immediately after the absorption of light by a NR is a fs scale redistribution of the energy by electronelectron interaction, which causes a rise in the kinetic energy of electrons. Electron-phonon scattering then causes thermal equilibration within the lattice, on the 1-4 ps timescale, which is dependent on the laser pump power, but independent of particle shape ${ }^{15,16}$ and size, within the 8 to $120 \mathrm{~nm}$ range. ${ }^{15-17}$ If the temperature of the lattice rises to values above its melting point, then changes in nanoparticle structure may occur within $\sim 30$ ps. $^{7}$ Subsequently, the accumulated energy is dissipated to the environment (solvent) by phonon-phonon interactions, 
over a time scale of the order of $100 \mathrm{ps}^{12}$ Thus, the length of a ns pulse exceeds the cooling time and results in a lower maximum particle temperature compared to a fs pulse with equal pulse energy.

Optical measurements of gold nanoparticles, such as characterization of nonlinear optical properties (e.g. with Z-scan technique $^{18}$ ) or imaging by two-photon microscopy, ${ }^{19}$ require information concerning the stability of nanorods illuminated with pulsed laser beams. Moreover, the long-term stability of NRs is needed for various nanorod applications, e.g. as biosensors and imaging agents. As was described by Zweifel et $a l .,{ }^{20}$ this can be achieved by surface modification of NRs by sulfide ions. However, to date, the photothermal stability of such nanoparticles has not been investigated. The influence of covalent thiol-gold bonds on the properties of nanorods is important, since it is often used for the attachment of (bio) molecules (DNA or proteins) to the NP surface. ${ }^{21,22}$ Zijlstra et $a{ }^{23}$ described specific covering of NR surfaces by small molecules with sulfide groups and provided a thorough analysis of the linewidth and the shift of the l-SPR band. It appears that binding of the molecules to the tips of the NRs causes a red-shift of the l-SPR band, independent of the thiol chain length; however the degree of coverage modulates the linewidth. These unique optical properties have been applied in sensing using single NPs. ${ }^{24,25}$

In this paper we present results concerning structure modification of NRs and their stability upon irradiation with femtosecond laser pulses, when the surface of NRs is stabilized with sodium sulfide $\left(\mathrm{Na}_{2} \mathrm{~S}\right)$. Here, we compare NRs stabilized with $\mathrm{Na}_{2} \mathrm{~S}$ and NRs without any additional surface modification, upon irradiation of the colloidal solutions by $800 \mathrm{~nm} 130 \mathrm{fs}$ laser pulses at $1 \mathrm{kHz}$.

To understand the response of NRs to temperature increase, the composition of the NRs as a function of the increasing temperature was studied using thermogravimetric analysis that allowed deduction of the content of volatile organic components of the ligand-covered nanorods.

The monitoring of reshaping of NRs with fs pulses was performed with UV-vis spectroscopy and transmission electron microscopy (TEM). We demonstrated that surface modification by sodium sulfide increases the stability of the irradiated nanorods and enabled greater control of the reshaping and melting processes. We also present new shapes of gold nanoparticles, which can be produced by post-synthesis modification of NRs with a laser beam.

\section{Synthesis of gold nanorods}

Gold nanorods were synthesized using the seed-mediated growth method in the presence of CTAB, following the procedure reported before. ${ }^{26}$ First, the primary nuclei, colloidal solution of $3.5 \mathrm{~nm}$ gold seeds, were prepared using a strong reduction agent of gold salts, ice-cooled borohydride, in the presence of citrate as a capping agent. The second step consisting of the rapid growth of gold nanoparticles was carried out in aqueous surfactant media. Ascorbic acid was then used as a weak reducing agent of the gold salt in the presence of CTAB micelles. Gold nanorods have a tendency to contract with time: after synthesis, a blue shift of the longitudinal surface plasmon absorption peak was observed. To arrest the shortening of the nanorods, $15 \mathrm{ml}$ of $1 \mathrm{mM} \mathrm{Na}_{2} \mathrm{~S}$ solution was added into the growth solution one hour after seed injection, ${ }^{20}$ and the solution was left for 15 minutes in a water bath before centrifugation. For comparison, the second batch of gold nanorods without $\mathrm{Na}_{2} \mathrm{~S}$ was kept in a water bath for 75 minutes without perturbation and then both samples were centrifuged at $1400 \mathrm{rpm}$.

\section{Thermogravimetric analysis experiment}

The gold nanorod solutions were left to dry on a heating plate for $12 \mathrm{~h} / 70{ }^{\circ} \mathrm{C}$. The dry samples were collected from a glass vessel, weighed, and transferred into aluminium crucibles. The TG curves were recorded on a computer-controlled Setrys TG-DTA 16 TA Instrument, under the following operational conditions: the heating rate was $5{ }^{\circ} \mathrm{C} \min ^{-1}$, the temperature range: $20-1500{ }^{\circ} \mathrm{C}$, sample weight of about $0.5 \mathrm{mg}$, using aluminum crucibles, under an $\mathrm{N}_{2}$ atmosphere (1.1 bar). The TG curves of CTAB powder were also measured for comparison with the NR samples.

\section{Gold nanorod melting experiment}

For the melting experiment, $3.9 \mathrm{ml}$ of the mixture of gold nanorods (1:4, stock solution: water) was poured into a $10 \mathrm{~mm}$ quartz cell; a stirring bar was placed at the bottom. The laser beam with the Gaussian radius $w_{0}=6.05 \mathrm{~mm}$ illuminated the center of a cell placed on a magnetic stirrer (500 revs per min). The experiment was performed using a Quantronix Integra-C regenerative amplifier operating at $800 \mathrm{~nm}$, delivering pulses of $<130 \mathrm{fs}$, at a repetition rate of $1 \mathrm{kHz}$. The absorption spectra were measured at room temperature using a Jasco V-670 UV-visNIR spectrophotometer.

The size and shape distributions of the particles formed after synthesis and at different times of irradiation were determined from TEM images of the evaporated solutions on carboncoated copper grids taken using a FEI Tecnai $\mathrm{G}^{2} 20$ X-TWIN transmission electron microscope.

\section{Results and discussion}

The addition of $\mathrm{Na}_{2} \mathrm{~S}$ during the synthesis of the nanorods influences their structure to a certain degree. Absorption spectra measured immediately after nanorod synthesis show significant differences in the position of the l-SPR between NRs with $\mathrm{Na}_{2} \mathrm{~S}$ (NRs-with- $\mathrm{Na}_{2} \mathrm{~S}$ ) and without $\mathrm{Na}_{2} \mathrm{~S}$ (NRs-without-Na $\mathrm{N}_{2} \mathrm{~S}$ ) (Fig. 1a). For NRs-with- $\mathrm{Na}_{2} \mathrm{~S}$ the l-SPR is placed at $833 \mathrm{~nm}$ while it is at $756 \mathrm{~nm}$ for NRs-without- $\mathrm{Na}_{2} \mathrm{~S}$. It is important to note that both mixtures were prepared with the same seed solution and volume, with identical growth solution and reaction time for direct and reproducible comparison.

Sulfide ions have a strong affinity for heavy metals in their ionic and metallic states, allowing metal surface passivation. ${ }^{27}$ 

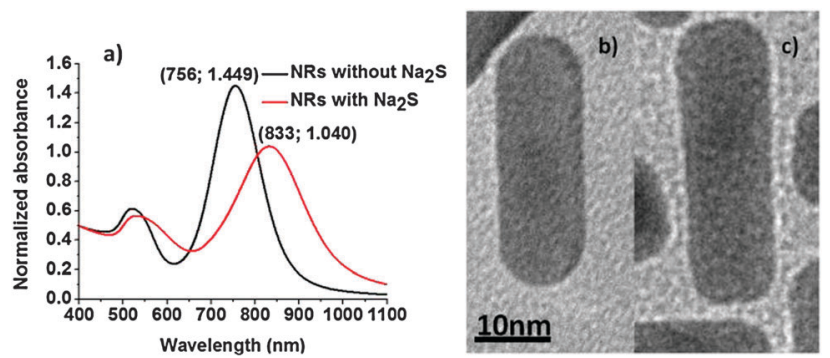

Fig. 1 (a) Absorption spectra of NRs-with- $\mathrm{Na}_{2} \mathrm{~S}$ and NRs-without-Na $\mathrm{N}_{2} \mathrm{~S}$. Selected nanorods from a NR mixture observed under TEM, (b) NRs-without-Na $\mathrm{N}_{2} \mathrm{~S}$, (c) NRswith- $\mathrm{Na}_{2} \mathrm{~S}$

Multiple factors contribute to the changes in a position and linewidth of the l-SPR band: they are predominantly due to changes in size and shape of the NRs (see below), but also modification of NR surface properties, such as the change in the refractive index of the surroundings by sulphide ions and decrease in the density of the free conductive electrons caused by $\mathrm{Au}-\mathrm{S}$ bonds may contribute. $\mathrm{Na}_{2} \mathrm{~S}$ is a small molecule, which facilitates the formation of the densely packed S-Au bonds across the entire NR surface. In addition, in our experiments $\mathrm{Na}_{2} \mathrm{~S}$ was added during nanorod synthesis, and thus may be incorporated not only as a ligand on the surface, but can form a $\mathrm{Au}_{2} \mathrm{~S}$ outer-most layer of the NR. Additionally, binding of the sulphide ions to gold atoms on the NR modulates the dielectric function in the vicinity of the NR surface (both in the ligand layer and in the immediate vicinity of that layer). A combination of all the above-mentioned contributions, together with the size and shape distribution certainly influence the optical properties of NRs, presented in Fig. 1a, where we observed a red-shift of $\sim 70 \mathrm{~nm}(\sim 140 \mathrm{meV})$ in l-SPR of NRs without and with $\mathrm{Na}_{2} \mathrm{~S}$ treatment.

TEM pictures (see Fig. $1 \mathrm{~b}$ and c, 4 and 5 at 0 s) provided information about average size leading to aspect ratios (a.r.) of $3.3 \pm 0.7$ and $3.5 \pm 0.8$ for NRs-without- $\mathrm{Na}_{2} \mathrm{~S}$ and NRs-with$\mathrm{Na}_{2} \mathrm{~S}$, respectively (Table 1). These results confirmed that $\mathrm{Na}_{2} \mathrm{~S}$ caused change in the NP dimensions when added to the GNR growth solution, however, as seen in Table 1 the average dimensions do not differ as much as might appear from inspection of the differences in the absorption bands which seem rather substantial (Fig. 1a). It was reported that the t-SPR band of the fusiform particles is wider due to the non-uniform width of the NPs. ${ }^{28}$ In our case the t-SPR band of the NRs stabilized by $\mathrm{Na}_{2} \mathrm{~S}$ appeared to contain two peaks, which may be attributed to the excitation of two transverse plasmons differing in frequency, as well as the presence in the solution of different shaped particles, such as spheres and cubes of various diameters.

Table 1 Summary of NR sizes from synthetic routes with and without $\mathrm{Na}_{2} \mathrm{~S}$ (average over $100 \mathrm{NRs}$ )

\begin{tabular}{lcc}
\hline & NRs-without-Na ${ }_{2} \mathrm{~S}$ & NRs-with-Na \\
\hline Average length [nm] & $31.0 \pm 3.2$ & $32.1 \pm 3.9$ \\
Average width [nm] & $9.7 \pm 1.6$ & $9.4 \pm 1.7$ \\
Average aspect ratio & $3.3 \pm 0.7$ & $3.5 \pm 0.8$
\end{tabular}

The TEM picture shows that nanorods with sulfide ions on the surface are wider at the ends and narrower in the middle of the structure (Fig. 1b). It is therefore possible that the widening of the t-SPR band corresponds to differences between surface plasmon excitation close to the ends of the NPs and that in the middle of this nanostructure. This result was not observed for NPs without $\mathrm{Na}_{2} \mathrm{~S}$. Of interest is also the influence of $\mathrm{Na}_{2} \mathrm{~S}$ on the shape of NR extremities: NRs-with- $\mathrm{Na}_{2} \mathrm{~S}$ were more square-shaped, compared to NRs-without- $\mathrm{Na}_{2} \mathrm{~S}$, which had more rounded ends (Fig. $1 \mathrm{~b}$ and $\mathrm{c}$ ). Sulfide ions were therefore also influencing the structure of the NRs, one may surmise that the crystalline faces involved in the interactions with the ligands are different with and without $\mathrm{Na}_{2} \mathrm{~S}$ treatment, thus, three-dimensional morphology and crystallography studies ${ }^{29}$ would be useful to evaluate the differences.

According to Zweifel et al. ${ }^{20}$ the surface treatment with sulfide ions is able to prevent NR degradation for months. Our studies confirm this observation, as we observed no change in the absorption spectrum of NRs up to three months after synthesis.

It needs to be mentioned that Zweifel et al. have already shown that the aging time and centrifugation influence the difference in width between the middle and the end of the nanostructure. ${ }^{20}$

\section{Thermogravimetric analysis}

To better understand the processes that may occur upon heating NRs, a thermogravimetric analysis of dried samples was performed (Fig. 2). The initial event observed following an increase of the temperature was residual water evaporation $\left(<100{ }^{\circ} \mathrm{C}\right)$ and $\mathrm{CTAB}$ degradation. The conjecture that the drop of mass at $\sim 260{ }^{\circ} \mathrm{C}$ is due to $\mathrm{CTAB}$ degradation was confirmed by the TGA measurement for a pure CTAB powder. We found that a formally dry sample (after two centrifugation rounds following the synthesis) contained $\sim 26 \%$ of the capping agent. The loss of weight must be the inorganic part of the sample was observed above $673{ }^{\circ} \mathrm{C}$, for NRs with and without $\mathrm{Na}_{2} \mathrm{~S}$. It should be noted

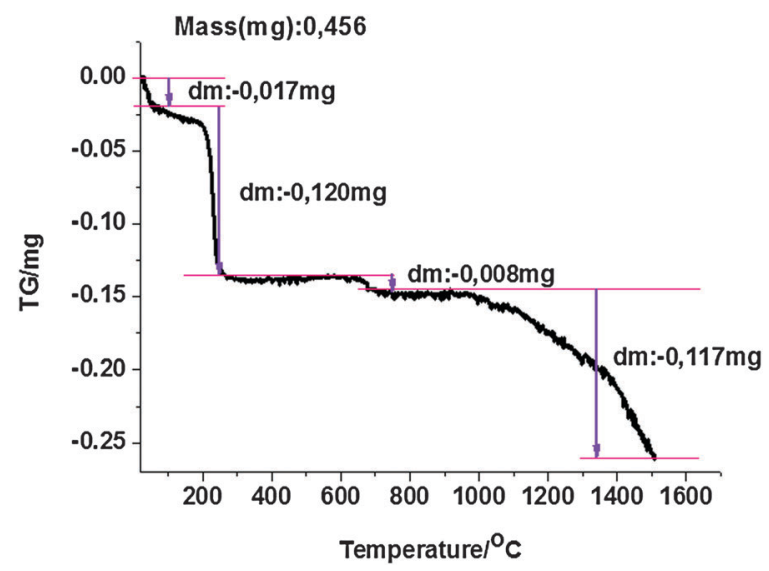

Fig. 2 The TGA results of a dried sample composed of NRs with $\mathrm{Na}_{2} \mathrm{~S}$. The first drop of the mass is due to water evaporation up to $100{ }^{\circ} \mathrm{C}$, the second is CTAB degradation at $\sim 260^{\circ} \mathrm{C}$, the third is due to the loss of the inorganic part of the sample at $673^{\circ} \mathrm{C}$ and the last broad decrease is attributable to gold evaporation. 
that bulk gold melts at $1064.18{ }^{\circ} \mathrm{C}$ and boils at $2856{ }^{\circ} \mathrm{C} .{ }^{30}$ Experimentally, it was shown that the thermally induced shape transformation of $38.2 \mathrm{~nm}$ gold ellipsoids into spheres occurs at $940{ }^{\circ} \mathrm{C}$ for particles deposited on silicon substrates. ${ }^{31}$ In the case of gold NRs investigated here, the loss of mass that may be attributed to gold starts at temperatures $\sim 950{ }^{\circ} \mathrm{C}$, which is clearly visible in Fig. 2. Samples of both NRs-with- $\mathrm{Na}_{2} \mathrm{~S}$ and NRs-without- $\mathrm{Na}_{2} \mathrm{~S}$ were investigated, but no significant difference between the TGA plots was observed.

\section{Reshaping of gold nanorods}

It has been widely reported that a colloidal solution of gold nanorods exposed to irradiation with fs pulsed laser with energy in the $\mu \mathrm{J}$ per pulse range evolves into spherical nanoparticles. ${ }^{16,32,33}$ These results were confirmed by TEM analysis of the samples before and after irradiation. ${ }^{8}$ Simultaneously, the absorption peak corresponding to the transversal mode increased indicating the enrichment of the solution with spherical gold nanoparticles. ${ }^{34}$ In addition, any morphological modification of the nanoparticles upon irradiation can be sensed by following the position of the l-SPR since it is extremely sensitive to the shape of the particles in solution. ${ }^{34}$

Nonlinear optical properties of NRs, ${ }^{18}$ which are exploited in multiphoton microscopy, ${ }^{11}$ may also depend significantly on the NR structure. Evaluating parameters that influence reshaping of NRs with laser irradiation should help in finding ways of controlling NR morphology post synthesis. We performed a series of irradiation experiments using a femtosecond laser, four representative examples were chosen and results are summarized in Table 2. First, we compared the influence of $\mathrm{Na}_{2} \mathrm{~S}$ on the stability of gold NRs with l-SPR band maximum placed outside the laser irradiation wavelength (NRs-1 and NRs-2). Subsequently, we studied the influence of the position of the l-SPR band vs. the irradiation wavelength on the NR stability (NRs-1 and NRs-4). Finally, we performed an experiment probing the rate of the shape change of NRs as a function of laser power (NRs-3 and NRs-4). In addition to parameters related to the nanorods under investigation and the laser parameters we estimated the average temperature rise of each nanorods in solution.

Assuming that electron-phonon thermalization occurs faster than external heat diffusion, the initial maximum temperature rise $\Delta T_{\mathrm{NP}}^{0}$ of a single NR due to irradiation with a single fs pulse can be calculated to be: ${ }^{35}$

$$
\Delta T_{\mathrm{NP}}^{0}=\frac{\sigma_{\mathrm{abs}} F}{V \rho_{\mathrm{Au}} c_{\mathrm{Au}}}
$$

where $\sigma_{\mathrm{abs}}$ is the absorption cross section of gold nanorods, calculated for the absorption at $800 \mathrm{~nm}$ of solutions of known NRs concentrations, determined as in ref. $18 F$ is the laser fluence at the sample, $c_{\mathrm{Au}}$ is the specific heat capacity of gold $\left(129 \mathrm{~J} \mathrm{~kg}^{-1} \mathrm{~K}^{-1}\right), \rho_{\mathrm{Au}}$ is gold density and $V$ is a single nanorod volume. The values of $F$ and $\Delta T_{\mathrm{NP}}^{0}$ are given in Table 2 . It is important to point out that the calculated average temperature increase, $\Delta T_{\mathrm{NP}}^{0}$, of a single $\mathrm{NR}$ was below or in one case just reached the threshold of gold vaporization $\left(\sim 950{ }^{\circ} \mathrm{C}\right)$ read from a TGA graph (Fig. 2). However, we have to take into account that the TGA experiment was performed in a nitrogen environment where the heat conductivity is smaller than in water.

We investigated the influence of the stabilization of the nanorods with $\mathrm{Na}_{2} \mathrm{~S}$ on the changes in NR shape under laser illumination. For NRs with $\mathrm{Na}_{2} \mathrm{~S}$, having the maximum of the l-SPR at $715 \mathrm{~nm}$ (NRs-1), a two-stage process was observed (Fig. 3a). Up to $\sim 20000$ laser shots $(20 \mathrm{~s})$ a blue shift and an increase of the l-SPR absorption band occurred simultaneously with the narrowing of the peak. This indicates an increase in the monodispersity of NRs, as well as a decreased aspect ratio of nanorods, essentially due to the increased width (see TEM images in Fig. 4, 0 and $12 \mathrm{~s}$ ) Further laser illumination, however, caused melting of the NR surface, transformation of numerous NRs into fused spherical nanoparticles, as observed in the TEM pictures (Fig. 4, $120 \mathrm{~s}$ ).

The l-SPR plasmon band of the NRs not stabilized by $\mathrm{Na}_{2} \mathrm{~S}$, with a maximum placed at $735 \mathrm{~nm}$ (NRs-2), shifted towards shorter wavelengths and decreased in intensity upon irradiation (Fig. 3b). This change is described as a one-step process of gradual shortening of NRs, which is confirmed by TEM pictures (Fig. 5). Finally, NRs melted and built a conjugated cluster composed of nanoparticles with random shapes, similar to NRs-1. The NRs with and without stabilization by $\mathrm{Na}_{2} \mathrm{~S}$ behaved differently during laser irradiation. With regard to the l-SPR band of the sample stabilized by $\mathrm{Na}_{2} \mathrm{~S}$ (NRs-1), an initial shift to a shorter wavelength was accompanied by a decrease of the a.r. With the time of irradiation the surface of the NRs started to melt. We observed welding of the NRs, indicated by an increase in the absorption above $900 \mathrm{~nm} .^{36}$ In the case of NRs without $\mathrm{Na}_{2} \mathrm{~S}$ (NRs-2), the l-SPR band decreased in intensity as a function of time; simultaneously with the formation of the band at longer wavelength, indicating that welding occurs much faster than in the case of NRs stabilized with $\mathrm{Na}_{2} \mathrm{~S}$. In order to compare samples with and without $\mathrm{Na}_{2} \mathrm{~S}$ illuminated at the edge of the absorption band, the number of laser shots required to reduce the extinction at the irradiation wavelength to 1/e was calculated (Fig. 6a and b).

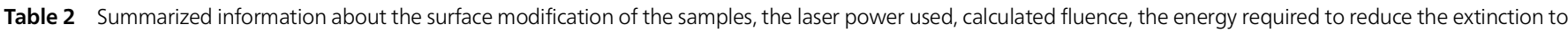
$1 /$ e of the initial value (no.1/e), as monitored by I-SPR band absorbance at $800 \mathrm{~nm}$, and increase of a nanorod temperature

\begin{tabular}{|c|c|c|c|c|c|c|}
\hline $\begin{array}{l}\text { Name of the } \\
\text { sample }\end{array}$ & $\begin{array}{l}\mathrm{Na}_{2} \mathrm{~S} \\
\text { modification }\end{array}$ & $\begin{array}{l}\text { Max l-SPR } \\
\text { position }[\mathrm{nm}]\end{array}$ & $\begin{array}{l}\text { Laser power } \\
{[\mathrm{mW}]}\end{array}$ & $\begin{array}{l}\text { Fluence per pulse } \\
{\left[\mathrm{mJ} \mathrm{cm}^{-2}\right]}\end{array}$ & $\begin{array}{l}\text { No. } 1 / \mathrm{e} \text { monitored } \\
\text { at } \lambda=800 \mathrm{~nm}\end{array}$ & $\begin{array}{l}\Delta T_{\mathrm{NP}}^{0}\left[{ }^{\circ} \mathrm{C}\right] \text { for } \\
\text { average power }\end{array}$ \\
\hline NRs-1 & Yes & 715 & 1060 & 3.6 & 3701 & 697 \\
\hline NRs-2 & No & 735 & 1060 & 3.6 & 2633 & 647 \\
\hline NRs-3-400 & Yes & 831 & 400 & 1.4 & 4660 & 415 \\
\hline NRs-3-1060 & Yes & 831 & 1060 & 3.6 & 3095 & 1065 \\
\hline
\end{tabular}



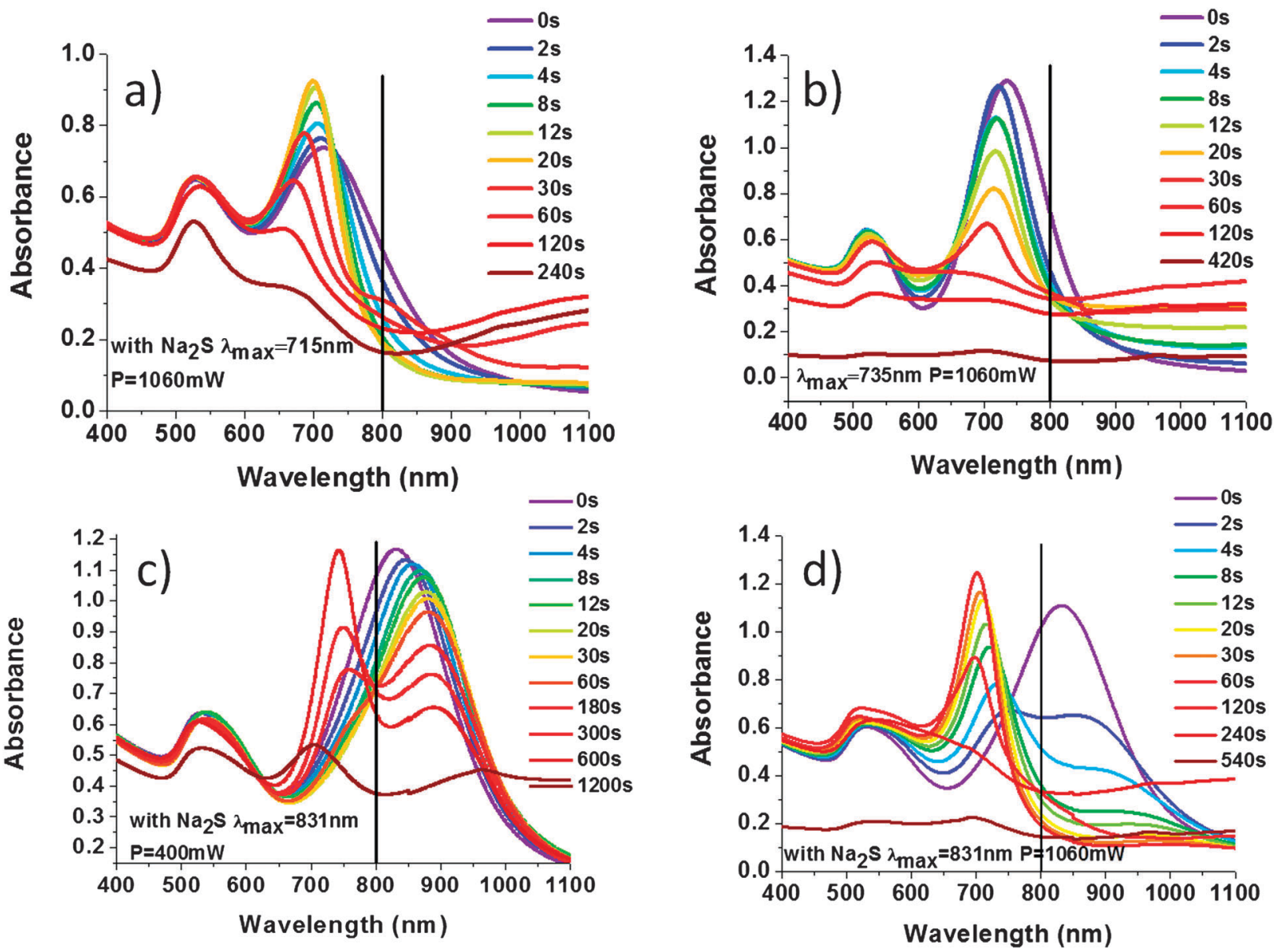

Fig. 3 Monitoring of the fs laser induced shape changes of NRs by observing the change in their surface plasmon resonance bands as a function of the exposure time.

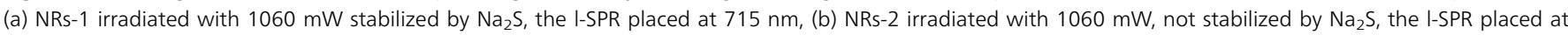
$735 \mathrm{~nm}$, (c) NRs-3 irradiated with $400 \mathrm{~mW}$, the I-SPR positioned at $831 \mathrm{~nm}$, (d) NRs-3 irradiated with $1060 \mathrm{~mW}$, the I-SPR is placed also at $831 \mathrm{~nm}$. The vertical bar at $800 \mathrm{~nm}$ denotes the laser wavelength.

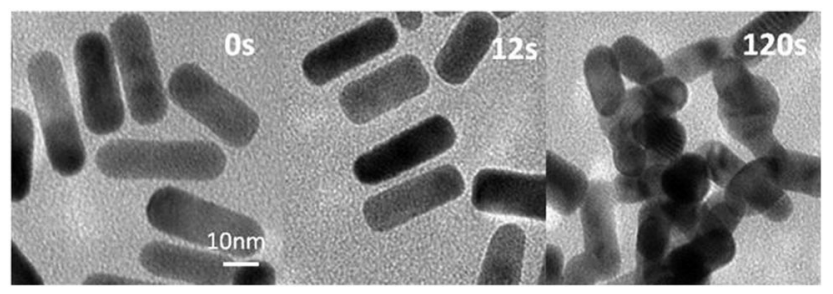

Fig. 4 TEM images of NRs-1 samples after exposure to $800 \mathrm{~nm}$ femtosecond laser irradiation. The laser fluence was $3.6 \mathrm{~mJ} \mathrm{~cm} \mathrm{~cm}^{-2}$. The power was $1060 \mathrm{~mW}$. During the irradiation the NRs become shorter, finally melt and build conjugated clusters.

The results presented in Table 2 clearly indicate that NRs with $\mathrm{Na}_{2} \mathrm{~S}$ have higher stability. Welding of nanoparticles occurs much faster in the case of NRs-2, which is indicated as a faster extinction at $800 \mathrm{~nm}$ upon irradiation (Fig. 6a and b). The measurements carried out on the additional samples gave us the average value of the number of laser shots required to reduce the extinction at the irradiation wavelength to $1 / \mathrm{e}$, when the laser power was $1060 \mathrm{~mW}$ : in the case of NRs with and without $\mathrm{Na}_{2} \mathrm{~S}$ was $2572 \pm 293$ and $3351 \pm 353$, respectively.

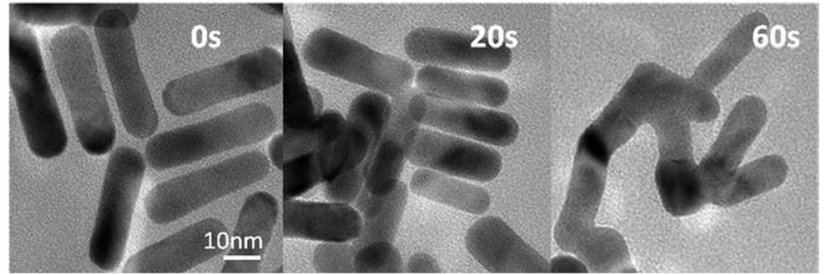

Fig. 5 TEM images of NRs-2 samples after exposure to $800 \mathrm{~nm}$ femtosecond laser. The laser fluence was $3.6 \mathrm{~mJ} \mathrm{~cm} \mathrm{~cm}^{-2}$. The nanoparticles decrease in length during irradiation, and build conjugated clusters similar to the sample NRs-1.

After confirmation of the increased stability of NRs with $\mathrm{Na}_{2} \mathrm{~S}$, we focused on the influence of the laser power on NR structure: samples NRs-3-400 and NRs-3-1060 are identical NR solutions with l-SPR maximum absorption at $831 \mathrm{~nm}$, irradiated at $800 \mathrm{~nm}$ with fs laser pulses with a power equal to $400 \mathrm{~mW}$ (corresponding to 400) or $1060 \mathrm{~mW}$ (corresponding to $1060 \mu \mathrm{J}$ per pulse) respectively. In this case we also calculated the number of laser shots required to reduce the extinction at the irradiation wavelength to $1 / \mathrm{e}$, as monitored by the absorption intensity at $800 \mathrm{~nm}$ (Fig. $6 \mathrm{c}$ and d), for NRs-3-400 it is 4660 and for NRs-3-1060 it is 3095. 

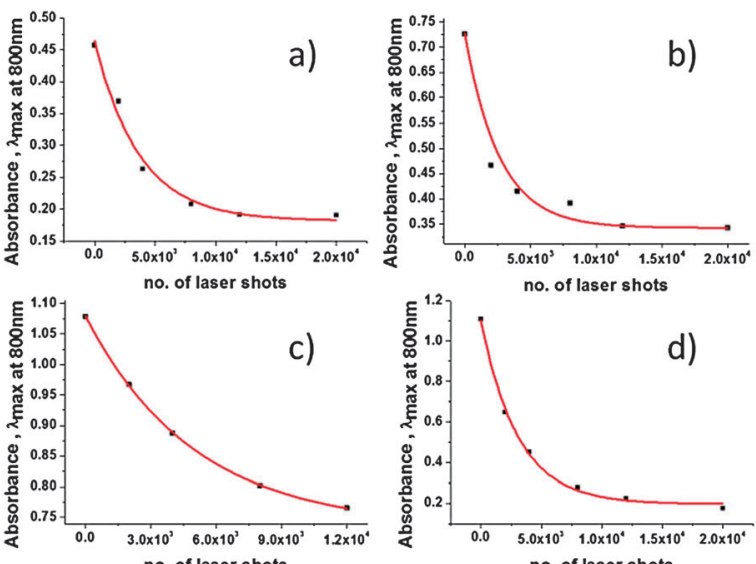

Fig. 6 Plot of the absorbance at $800 \mathrm{~nm}$ as a function of the number of laser shots. The solid lines are fits to the data points, which give the number of laser shots required to reduce the NR absorbance in $3900 \mu \mathrm{L}$ solution to $1 / \mathrm{e}$ of the initial value (no.1/e), samples: (a) NRs-1 $\left(3.6 \mathrm{~mJ} \mathrm{~cm}{ }^{-2}\right)$, (b) NRs-2 $\left(3.6 \mathrm{~mJ} \mathrm{~cm}^{-2}\right)$, (c) NRs-3-400 (1.4 mJ cm $\mathrm{cm}^{-2}$ ), (d) NRs-3-1060 (3.6 mJ cm $\left.{ }^{-2}\right)$.

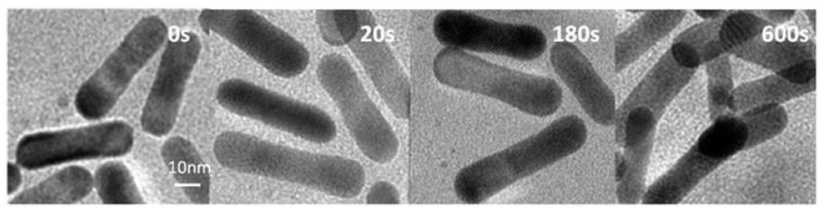

Fig. 7 TEM images of NRs-3-400 samples after exposure to $800 \mathrm{~nm}$ femtosecond laser. The laser fluence per shot was $1.4 \mathrm{~mJ} \mathrm{~cm}^{-2}$. The width of NRs decreased, but the sizes of the ends remained unchanged during irradiation.

For NRs-3-400, several steps of shape transformation were observed (Fig. 3c). At first, the red shift of the l-SPR was caused by a shape transformation of NRs with the l-SPR at $800 \mathrm{~nm}$. This was followed by spectral hole burning after $\sim 60000$ laser shots $(60 \mathrm{~s})$, indicating the formation of two populations of the NRs with a different a.r. (see TEM in Fig. 7 at $180 \mathrm{~s}$ ) certainly due to the melting of rods that were in exact resonance with the laser. Upon $180 \mathrm{~s}$ of irradiation, we simultaneously observed an increase in the absorption band centered at $\sim 720 \mathrm{~nm}$ and a decrease of the absorption band at $900 \mathrm{~nm}$. We could observe similar spectral changes (Fig. 3d) but different shapes of NRs (Fig. 8) when the same sample (NRs-3-1060) was irradiated with $1060 \mathrm{~mW}$ power.

Higher energy laser pulses caused breaking of the single crystal structure of NRs in the first few seconds of irradiation. Bending and transformation into banana-shaped nanoparticles was observed for a part of the NR population ( $\sim 10 \%)$ (Fig. 8). We suggest that the banana-shaped nanoparticles were formed from NRs with defects on the surface. Banana-shaped NPs appearing at the early stage of the shape transformation simultaneously demonstrate that the starting location of the atomic-scale restructuring is at the centroid of the Au NRs. ${ }^{37}$ The population with surface damage was stable after the first laser shots, but then began to contract.

No red-shift of l-SPR was observed for the first few seconds of irradiation, but there was a significant drop in the absorption band after 2000 laser shots (2 s) (Fig. 3d) and the spectral

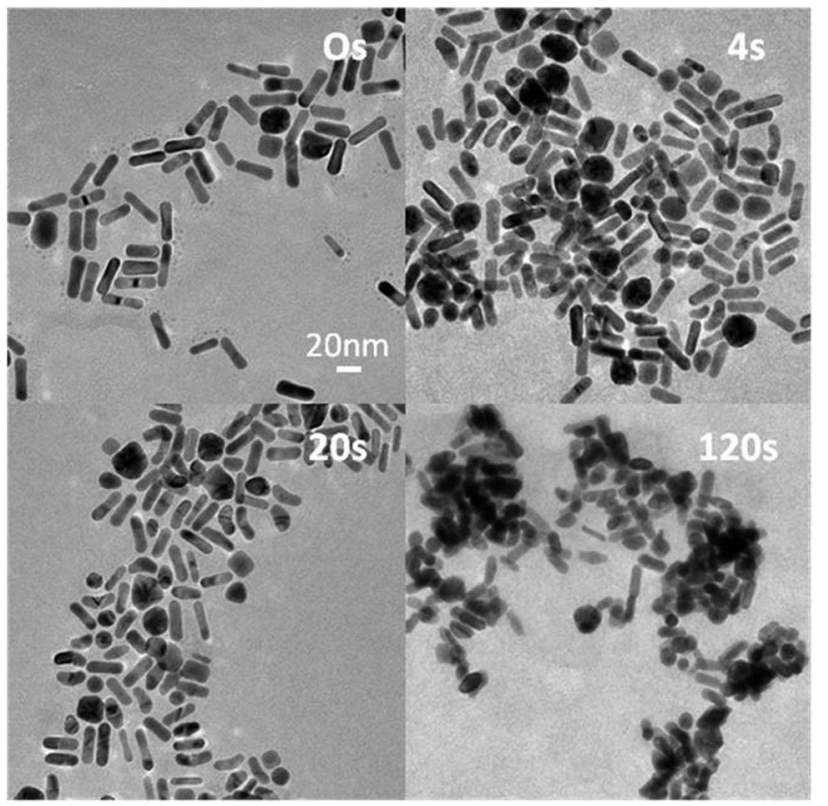

Fig. 8 TEM images of NRs-3-1060 samples after exposure to $800 \mathrm{~nm}$ femtosecond laser. The laser fluence per shot was $3.6 \mathrm{~mJ} \mathrm{~cm} \mathrm{~cm}^{-2}$. After $4 \mathrm{~s}$ (4000 laser shots) NRs with surface defects start to bend and reshape into banana-shaped nanoparticles. Over time, the shape changes into more rounded nanoparticles.

hole burning was observed. Subsequently, a blue-shift and narrowing of the plasmon resonance to the NRs with the maximum l-SPR at $\sim 700 \mathrm{~nm}$ was observed. After $\sim 20000$ laser shots $(20 \mathrm{~s})$, one l-SPR band was formed, shifted from the original position by $\sim 115 \mathrm{~nm}$. A change in the size distribution appeared: the average NR width increased, where simultaneously the average NR length decreased. ${ }^{38}$ Further irradiation led to reshaping of NRs into round nanoparticles (Fig. 8, $120 \mathrm{~s}$ ).

We suppose that the twin-plane, single crystal structure NRs with surface defects may start to transform into polycrystalline nanoparticles upon irradiation with fs laser (Fig. 9). The transformation is likely to start at the surface and then propagate into the interior of the NR. Despite the broad range of gold nanoparticle shapes reported to date, the synthesis of bananashaped gold nanoparticles has not been previously described.

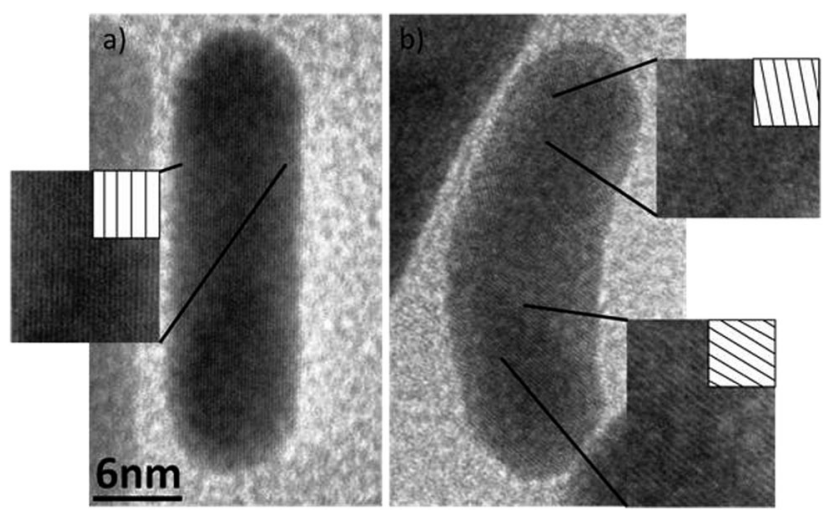

Fig. 9 Comparison of the nanorod with single crystal structure (a), and bananashaped nanoparticle with twin-plane defect (b). 
The present results demonstrate that laser-induced shape transformation of gold nanorods can provide new shapes of gold nanoparticles, unavailable with other methods.

\section{Conclusions}

In the present work, the structural stability of NRs with surfaces modified with $\mathrm{Na}_{2} \mathrm{~S}$ was studied under the illumination with a fs laser. A complementary thermogravimetric analysis of the NR sample demonstrated that the loss of sample weight due to the evaporation of gold could start at temperatures below $1000{ }^{\circ} \mathrm{C}$, which is much lower than the boiling point of bulk gold $\left(2856^{\circ} \mathrm{C}\right)$. Irradiation with fs laser showed that NRs treated with $\mathrm{Na}_{2} \mathrm{~S}$ were more stable during illumination, compared to NRs with the l-SPR band placed in a similar range, but with unmodified surfaces. When NRs with $\mathrm{Na}_{2} \mathrm{~S}$ were illuminated with a laser wavelength on the slope of the l-SPR band, the size distribution and the l-SPR bands became narrower. Similar effects were not observed in the case of NRs without $\mathrm{Na}_{2} \mathrm{~S}$. These nanostructures were less stable during high power laser irradiation as evidenced by a fast decrease in l-SPR intensity and the rapid welding of the nanoparticles. NRs with $\mathrm{Na}_{2} \mathrm{~S}$ modified surfaces allowed easier control of the position of the absorption band during fs laser irradiation. When laser illumination was applied at the wavelength corresponding to the maximum of the l-SPR

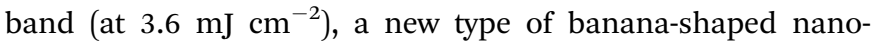
particle was formed, which constituted approximately $10 \%$ of the nanoparticles. In the case of a moderate laser fluence (1.4 $\mathrm{mJ} \mathrm{cm}^{-2}$ ), two populations of NRs were formed having different aspect ratios, and these were further transformed into NPs with smaller aspect ratios, but no banana-shaped NPs were observed. Monodisperse solutions with NPs of a given aspect ratio could be obtained, before the transformation of NRs into welded aggregates. These results confirm the significant contribution of the surface melting in the photoinduced transformation of gold nanorods as well as show the production of new shapes of gold nanoparticles by laser irradiation under controlled conditions.

\section{Acknowledgements}

This work was supported by the Foundation for Polish Science under the "Welcome" Program, the financial support from the fellowship co-financed by European Union within European Social Fund POKL "Mloda Kadra", the French Embassy via cotutelle programme, a statutory activity subsidy from the Polish Ministry of Science and Higher Education for the Faculty of Chemistry of WUT, and by NCN Harmonia project UMO-2012/04/M/ST5/00340.

\section{Notes and references}

1 S. Link and M. A. El-Sayed, J. Phys. Chem. B, 1999, 103, 8410-8426.

2 P. Mulvaney, Langmuir, 1996, 12, 788-800.
3 S. Hashimoto, D. Werner and T. Uwada, J. Photochem. Photobiol., C, Photochem. Rev., 2012, 13, 28-54.

4 C. Burda, X. Chen, R. Narayanan and M. A. El-Sayed, Chem. Rev., 2005, 105, 1025-1102.

5 G. V. Hartland, Chem. Rev., 2011, 111, 3858-3887.

6 S. Link and M. A. El-Sayed, Int. Rev. Phys. Chem., 2000, 19, 409-453.

7 S. Link, C. Burda, B. Nikoobakht and M. A. El-Sayed, J. Phys. Chem. B, 2000, 104, 6152-6163.

8 S. Link, C. Burda, M. B. Mohamed, B. Nikoobakht and M. A. El-Sayed, J. Phys. Chem. A, 1999, 103, 1165-1170.

9 S. Link and M. A. El-Sayed, J. Chem. Phys., 2001, 114, 2362-2368.

10 S. S. Chang, C. W. Shih, C. D. Chen, W. C. Lai and C. R. C. Wang, Langmuir, 1999, 15, 701-709.

11 P. Zijlstra, J. W. M. Chon and M. Gu, Phys. Chem. Chem. Phys., 2009, 11, 5915-5921.

12 M. Perner, P. Bost, U. Lemmer, G. von Plessen, J. Feldmann, U. Becker, M. Mennig, M. Schmitt and H. Schmidt, Phys. Rev. Lett., 1997, 78, 2192-2195.

13 T. S. Ahmadi, S. L. Logunov and M. A. El-Sayed, J. Phys. Chem., 1996, 100, 8053-8056.

14 J. H. Hodak, I. Martini and G. V. Hartland, J. Phys. Chem. B, 1998, 102, 6958-6967.

15 N. G. Khlebtsov, Quantum Electron., 2008, 38, 504-529.

16 A. Biesso, W. Qian and M. A. El-Sayed, J. Am. Chem. Soc., 2008, 130, 3258-3259.

17 X. Huang, I. H. El-Sayed, W. Qian and M. A. El-Sayed, J. Am. Chem. Soc., 2006, 128, 2115-2120.

18 J. Olesiak-Banska, M. Gordel, R. Kolkowski, K. Matczyszyn and M. Samoc, J. Phys. Chem. C, 2012, 116, 13731-13737.

19 J. Olesiak-Banska, M. Gordel, K. Matczyszyn, V. Shynkar, J. Zyss and M. Samoc, Nanoscale, 2013, 5, 10975-10981.

20 D. A. Zweifel and A. Wei, Chem. Mater., 2005, 17, 4256-4261.

21 R. Ishmukhametov, T. Hornung, D. Spetzler and W. D. Frasch, EMBO J., 2010, 29, 3911-3923.

22 T. Fujiwara, K. Ritchie, H. Murakoshi, K. Jacobson and A. Kusumi, J. Cell Biol., 2002, 157, 1071-1081.

23 P. Zijlstra, P. M. R. Paulo, K. Yu, Q. H. Xu and M. Orrit, Angew. Chem., Int. Ed., 2012, 51, 8352-8355.

24 P. Zijlstra, P. M. R. Paulo and M. Orrit, Nat. Nanotechnol., 2012, 7, 379-382.

25 I. Ament, J. Prasad, A. Henkel, S. Schmachtel and C. Sonnichsen, Nano Lett., 2012, 12, 1092-1095.

26 T. K. Sau and C. J. Murphy, Langmuir, 2004, 20, 6414-6420.

27 M. D. Lay, K. Varazo and J. L. Stickney, Langmuir, 2003, 19, 8416-8427.

28 H. M. Chen, H.-C. Peng, R.-S. Liu, K. Asakura, C.-L. Lee, J.-F. Lee and S.-F. Hu, J. Phys. Chem. B, 2005, 109, 19553-19555.

29 H. Katz-Boon, C. J. Rossouw, M. Weyland, A. M. Funston, P. Mulvaney and J. Etheridge, Nano Lett., 2011, 11, 273-278.

30 G. W. C. Kaye and T. H. Laby, Tables of physical and chemical constants, Longman, London, UK, 15th edn, 1993. 
31 S. Inasawa, M. Sugiyama and Y. Yamaguchi, J. Phys. Chem. B, 2005, 109, 9404-9410.

32 A. J. Haes, D. A. Stuart, S. Nie and R. P. Van Duyne, J. Fluoresc., 2004, 14, 355-367.

33 X. Huang, S. Neretina and M. A. El-Sayed, Adv. Mater., 2009, 21, 4880-4910.

34 E. Cottancin, M. Broyer, J. Lerme and M. Pellarin, Handbook of Nanophysics, CRC Press, 2010, ch. 24, pp. 1-25.
35 G. Baffou and H. Rigneault, Phys. Rev. B: Condens. Matter Mater. Phys., 2011, 035415, 1-13.

36 J. Kumar, X. Wei, S. Barrow, A. M. Funston, K. G. Thomas and P. Mulvaney, Phys. Chem. Chem. Phys., 2013, 15, 4258-4264.

37 S. Link, Z. L. Wang and M. A. El-Sayed, J. Phys. Chem. B, 2000, 104, 7867-7870.

38 S. Nie and S. R. Emory, Science, 1997, 275, 1102-1106. 